\title{
EDUCATIONAL
}

TECHNOLOGY

\section{How media materials are used in university instruction: Reports of selected university faculty members}

\author{
Anne L. Russell \\ Department of Librarianship and Teaching Studies \\ Kelvin Grove Campus \\ Brisbane College of Advanced Education
}

How are media materials used in University instruction? How does their use influence class preparation and the mechanics of lecturing? How do classroom facilities and centralised instructional media services influence the nature of media materials use by individuals?

This descriptive study examines the personal perspective of twenty selected university media users. The complete study (Russell, 1981) involved an analysis of personal perceptions as to why, what, when, and how media materials are used in university instruction. This paper will report findings related to the last of these four questions: namely, 'How are media materials used in university instruction?'

The media materials identified in this study are limited to electronically augmented materials such as overhead transparencies, slides and $16 \mathrm{~mm}$ films.

\section{Rationale for the study}

Research concerning the use of media materials to enhance learning has provided contradictory evidence as to their effectiveness in the learning process (Campeau, 1974; Jamison, Suppes and Wells, 1974; Parkhurst, 1975; and Schramm, 1977). While researchers look for evidence of media effectiveness, an important variable seems to have been overlooked -- the teacher.

I believe the ways a teacher presents information to learners can influence the use and effectiveness of media materials in an instructional situation. If a teacher believes the use of media materials is important for student 
learning and feels comfortable using such materials, that teacher is likely to use those materials effectively.

Some researchers (Tobias, 1966,1969; Armsey and Dahl, 1973; Purdy, 1973, 1975; Dodge, 1974; and Schramm, 1977) have studied teachers involved in mediated or programmed instruction; my interests concern those teachers who integrate media materials within their personal lecture presentations. How do those teachers perceive their use of media materials as an instructional strategy?

\section{Methodology}

For this descriptive study a questionnaire and personal interview were used to gather information concerning the personal beliefs of media use by lecturers who frequently used media materials in their instruction.

Only faculty members at the University of Oregon who were known to use media materials frequently in their instruction were selected to participate in the study. I formulated a list of lecturers who used media materials in their instruction in consultation with the staff of the Instructional Media Centre and students from many subject areas in the University.

Twenty lecturers were invited to participate in the study. To ensure a wide cross-section of subject interests, lecturers were selected from the following subject departments: Anthropology' Architecture, Art Education, Art History, Biology, Dance, Education, Educational Policy and Management, Film and Television Studies' Geography, German, Health Education, History, Journalism, Marketing, Music, Psychology, Recreation and Park Management, Sociology, and Spanish.

\section{Profile of the Study Group}

Age: The ages of the respondents ranged from early thirties to early sixties.

Sex: The study group approximated the ratio of male and female lecturing staff at the University of Oregon -- sixteen males $(80 \%)$ and four females $(20 \%)$ took part in the study.

Academic Qualifications: Fourteen (70\%) of the respondents have Ph.D. or Ed.D degrees.

Number of Years Teaching in Higher Education: The average number of years respondents had taught at college or university level was 15 years. Every respondent had taught at this level for at least four years.

Academic Preparation in Media Production or Use: Fourteen (70\%) of the respondents had had no formal training in media production, or the use of media materials for education. 
Location: The University of Oregon is a research-orientated university where faculty members are required to publish books and articles in quality research journals, in addition to normal university teaching, advising, and committee responsibilities. At the time of the study the university was suffering large financial cuts and this factor was frequently mentioned by the study group when discussing costs and quality of university facilities affecting their use of media materials in instruction.

\section{Development of the Data Gathering Instruments}

A combination of questionnaire and personal interview was used to collect data for this descriptive study. The questionnaire and interview schedule were each developed specifically for this study. Each was pilot tested and revised before being presented to the study participants.

The self-administered questionnaire was presented to each respondent at an initial twenty minute personal interview. The responses provided basic information related to the background experience of the respondents concerning their training, and use of, media.

The main (hour-long) interview was recorded on audiotape. This interview was designed to encourage respondents to explore and report their reasons for developing instructional strategies that require the use of media materials.

In relation to the general question, 'How are media materials used in instruction?', I posed the following questions:

1. How does the use of media materials affect class preparation?

2. What are the mechanics of media materials use in the classroom?

3. Do classroom facilities affect the use of media materials in instruction?

4. How does the centralised Instructional Media Centre influence the nature of media materials' use?

In response to my questions, respondents spoke at length on how media materials are used in their instruction.

The question sequence of the main interview was flexible in order to accommodate the natural direction of conversion. All questions were covered in each interview.

\section{Analysis of the Data}

The data collected from the questionnaires was translated into frequencies and averages. The tape-recorded interviews were systematically analysed and interpreted through content analysis. The content analysis was carried out by: 
1. Listening to each interview tape and transcribing significant information to provide part-transcripts approximately sixteen pages in length.

2. The part-transcripts were analysed for content pertaining to the questions posed to the respondents.

3. This content was further categorised into sub-headings pertaining to each interview question.

\section{The findings}

Words of wisdom and enthusiasm came in all directions during the interviews. Though $70 \%$ of the respondents were untrained in media use, their gut level responses to my questions produced some textbook answers concerning how they use media materials in their instruction Media materials are typically integrated into a lecture to provide illustration, emphasis and variety. Both physical and personnel support services influence how media materials are used in university instruction at the University of Oregon.

The findings of the descriptive study are best reported in the words of the respondents. How media materials are used in instruction will be reported in relation to class preparation, mechanics of classroom use, classroom facilities, and influence of the Instructional Media Centre.

\section{Preparation for Class}

The respondents generally consider preparation for classes involving the use of media materials will take longer the first time a course is taught. The preparation of new media materials requires creation time, while commercial media materials need time to be located and preparation is not so time-consuming.

It is interesting to note that each of the selected respondents has taught for a minimum of four years. Perhaps the first few years of teaching do not permit time for media preparation and selection of commercial materials.

In the words of one respondent:

My preparation for class is very uneven. If I am actually preparing materials, it takes a great deal of time. Now once you get the materials prepared it is like having a library -- it is possible to go to the cabinet, pull out the illustrations or particular package you have prepared.

Seven respondents reported that their use of media took extra preparation time.

The time-consuming preparation of worthwhile media materials is like building one's own library of resources. 
At certain times, using the media requires a great deal more preparation. The tapes I will use today I did several months ago. If I didn't have them ready I would spend three of four hours getting the packages ready for class. That is time-consuming. I guess that is one reason why some professors stay away from creating materials -- there is not enough time.

Once time has been spent in preparation of media- related instructional strategies, the next time the subject is taught, preparation time is available for identifying further media materials.

There are times that media use really helps me in terms of time. It provides me with forty- five minutes fill-in space so there is actually less time I have to be concerned about that particular class. That shakes me loose to work on other classes or to prepare new materials ... it's a kind of constant thing. I would never sit ... I really try to use new materials every class -- I don't want to be bored either.

Frequently the nature of media materials requires advance planning. Films, for example, are usually accessible to faculty from many institutions and need to be booked several months in advance. Special course planning, to accommodate films, tend to place limitations on the flexibility of how a course will run:

Media use forces me to be more organised than I would otherwise be, and forces me to stay closer to some kind of schedule -- because I order the films at the beginning of the term ... I have them scheduled for certain dates so I have to make sure that I am dealing with the appropriate (subject) material (when they arrive).

Another respondent is not prepared to be manipulated by previously scheduled films:

I stopped using films ... It was always a hassle to schedule films to get them there, to play them ... I had to order the films some large period of time before I want to show them -- two months or something ... The way I want to use film is to come to a particular point in the lecture where that film is relevant ... Now I can never be sure whether that is going to come on Monday or Wednesday or Friday of that particular week. Now when the film comes out of sequence it does you no good, or some good, but very little good. It is just not worth the hassle.

Preparation for including slides within a lecture is described by one respondent:

For each hour lecture it takes about two hours to pull the slides and arrange them. It took much longer when I first arrived here -- because I didn't know how the slides were filed. I now know where the slides are. Some preparation is done at home and some (at the University) usually the evening or two days before (a lecture). This gives me some time to reflect on what I am going to talk about -- or I might think of a different way of arranging my lecture ... or pulling some material out that is tangential ... 
There are several light-tables in the slide room ... You lose a certain immediacy when you do it several days in advance.

Sorting slides into a sequence appropriate for a visually enhanced lecture is like sorting notes for a spoken lecture.

Preparation for class involves setting up equipment in classrooms. Respondents resent having to haul equipment to their classroom and set it up. This is a major factor in promoting a negative attitude toward the use of media materials at the University of Oregon.

There are some practical problems that interfere with the use of all these things ... Depending on where (I am) teaching ... I have to pick up the overhead projector ... carry it to the classroom, set it up and after class take it ... back to the location where I got it. That's a pain. I suspect I would use overheads even more if by some wave of my hand I could make one appear in every classroom ... It is a pain and I guess I do resent having to do it.

and:

On certain days if I want to show something in class I have to haul a bunch of materials up to the next floor myself -- there is no permanent place to story (equipment). I have got to set it all up and take it all down before the next class begins -- trip over wires so that the next person can get in -- he or she may not be using media materials and may be upset that it takes so much time. It limits my enthusiasm temporarily, but I will still do it because I think it is very valuable.

In spite of preparation time and other hassles relating to use of media materials and equipment, respondents will use media materials in their instruction because these form an essential ingredient for their presentations.

\section{Mechanics of Classroom Use of Media Materials}

Typically respondents reported their class presentations used media materials integrated within the lecture presentation. Slides and overhead transparencies are used to provide illustration or emphasis during a verbal presentation, while $16 \mathrm{~mm}$ film generally is introduced, shown, and followed by class discussion.

The thinking and planning behind a typical lecture is described by one respondent:

Let's take the introductory Psychology class -typically a fifty-minute class, three times a week. The class would start with an overhead of the outline ... and then I would both lecture and use the overhead projector to write down words that were unfamiliar, to sketch out graphs, etc. I would also have from three to ten prepared transparencies for that lecture -- very seldom would there be a lecture where I didn't have a prepared transparency. I 
would use both the roll with my own notes on it and prepared transparencies ... it's typical to have both slides and transparencies ... If there is a film, I know how long the film is and at which point to put it in. I will take eight or ten minutes to talk about it and then we will show the film and I will have ' $x$ ' minutes left. I know how the whole hour is going to be, because I know approximately how many minutes the film is going to take. Both films and slides tend to force a structure more than the overheads do.

Media, in this way, becomes an integral part of the class and does not stand apart from a straight lecture presentation.

Four respondents reported they would use a variety of media formats in a typical lecture. The explanation given by one respondent:

I like variety ... If I am going to use overheads I will use several and then I will stop and have several slides. If I have to flip back and forth I will apologise to the class because it is distracting and takes time. Maybe it wakes them up a bit! One hundred slides in a row is deadening, actually.

Three respondents reported they would use only one media format during any lecture:

I don't use two different sets of media equipment in one lecture. I will try to make a choice. Essentially there are twenty lectures in a term and I do not want to get myself or students relying on input without the appropriate amount of expressive activities ... Media tends to become very passive if you let it ... It is a kind of discipline I follow. To get along with one media format and ensure that there is time for the expressive part that follows the receptive part. Just passive receptiveness is very limiting.

Each media format is used in a special manner by respondents. Slides are reported as being a cue and stimulus for student reaction:

(The slides) trigger my response ... The paces of slides allows you to just sit and watch them. It is possible ... that you can show slides and talk about them and stop talking and leave the slide on, and the students' minds keep on working. It is all holding in a kind of precise ambiguity or a kind of openness ... With up to 100 people we can have a discussion, after that it is pretty hard ... It is absolutely necessary to have discussions ... partly because of the many messages that come from slides ... I use slides like a vocabulary.

Overhead projectors are one of the most frequently used pieces of equipment:

I set up ahead of time and have something on the screen ... (so the people know they are at the right place). I also put on early the goals and objectives ... and run through those with the people so they know what to look for. I utilise (the overhead projector) a good part of the time, but also try to remember that there are times when I am not utilising it, and turn it off so 
that the light is not on, and (students) are not being distracted by something that is not being (discussed).

Another respondent describes his typical use of the acetate roll with the overhead projector:
I stand in front of the students, beside the overhead projector and just start giving the lecture and writing down as I go ... important things -- my outline, the topic or question I am approaching, I discuss the experiment that bears on that question, draw a diagram, expect students as a group to respond .... and if someone asks a question that relates to what I talked about ten minutes ago, I can roll it back and there it is and I can amplify right there.

This respondent also uses the overhead projector creatively to demonstrate various biological concepts. He used a mutant fly which is temperature sensitive and puts it in a clear container on the overhead projector -- the heat from the projector makes the fly active. Various aspects of the operation of the central nervous system are demonstrated.

One typical class where film is used is described as follows:

\begin{abstract}
I have to transport the class over to the Instructional Media Centre to show films in a studio because I don't have a classroom that is appropriate for showing films ... Generally when everyone finally remembers that they are supposed to be over there instead of in the classroom already five minutes of the period have gone. I usually give a very brief introduction to remind them what they are seeing and to highlight a couple of things that they are going to see in the movie and tell them to pay special attention to that. I ask the projectionist to turn it on. Generally there is at least one breakdown before we get very far, that is not their fault -- the equipment is old and there is no money to buy any new equipment. We see the movie -- people generally watch rather intently -- I don't know if that is because the movie is that exciting or just because they think there is likely to be something on the exam about the movie, and there usually is. If the movie ends before the period is over, I go back to the front of the class and ask if people have any questions about the material they have been seeing. And I also ask them to do a little evaluation -- what did they think of the film? What did they get out of it? I notice that they sometimes start taking notes if I say something or answer a question. They do not realise that the comments from their fellow students are much better than some of the comments I make!
\end{abstract}

\title{
The Importance of Suitable Classroom Facilities
}

The respondents generally believe the classroom facilities at the University of Oregon are not satisfactory:

The classroom facilities are nowhere near ideal ... I would say they are not really even adequate. I suppose that at some level the political decision is where you spend your money. 
Classroom facilities are a major consideration in the successful promotion of the use of media resources. In this study most respondents reported negative feelings toward teaching spaces assigned to them. Where media use is essential for a particular course some respondents have insisted on being allocated a suitable room:

Some classrooms are not very good. One did not have good screens, and I gave up on a few films. But for the World Health class I made sure that I have a good room. If you don't have a good image there it is really distracting ... If the facilities are not good I eliminate using some media that I would normally use.

One respondent was insulted when it was suggested he should alter his teaching style to suit the classroom facilities:

I found that someone had anchored the podium to the platform in the front and fastened the (slide projector remote control) to the wall so that you couldn't walk around with the trigger in your hand ... I asked if anyone could please change this because I have to be able to walk around when I talk with the trigger in my hand and point to things on the image ... (They) started telling me that I should change my lecture style!

\section{The Value of the Instructional Media Centre (IMC)}

The success of the Instructional Media Centre is dependent on the attitudes of the IMC staff and the faculty members who use the services. The IMC has much to offer, and the present staff is reported on in favourable terms, although negative memories remain.

One respondent used the IMC services when he first arrived at the University of Oregon nine years ago, and found the services to be unsatisfactory. His knowledge of the current services offered were negligible and he spoke of a person who left the IMC six years ago:

I did use (the IMC) initially but don't any more ... I had nothing but unhappy experiences with ' $X$ ' ... I finally gave it up. It was just too hard.

On the other hand present users of the IMC reported being generally happy with the services offered and nature of the personnel:

The IMC staff are excellent, they are organised and they will break their backs ... These people are very dependable ... Their newsletters are very important. They ask you to be patient ... It's a feeling of belonging to something, where you know they are trying.

and:

The IMC staff are great at consultation and continuity of support. They take someone who doesn't know something and help ... They are good at furnishing someone who has expertise, or they will proceed to give us a lesson so we can become independent ... The co-operation has been fantastic ... with ideas and the kind of things I need forthcoming. 
A perennial problem with service centre staff seems to be high turnover rate.

I like to use films, but it is a pain for me to schedule them ... The staff at the media centre has had a lot of turnover. I frequently feel it's time for me to train a new film programmer again, and that gets to be old after a while ... the inevitable slip-ups I have noticed this year were a lot easier to bear and there were a lot fewer of them because of this particular group of people.

The IMC staff produces a two-page newsletter providing information about current services and new films added to the film collection. An insightful comment was made by one respondent.

The media centre offers a lot. They publicise with their fliers, but one also had to be oriented towards using media before that clicks.

\section{Discussion}

It follows from the study that the key to how media materials are used in university instruction lies with the orientation of the lecturer. The lecturer who believes in using media materials in instruction will generally take the time and effort required to incorporate media into many lectures, especially when the materials and equipment are available without hassle.

How can lecturers who do not use media materials be convinced of the importance of using media materials in their lectures? It is only with constant use that lecturers will become comfortable in their integration of media materials as part of their teaching strategies. The initial use of media materials must meet with success, especially ensure optimum conditions for projection and sound and consequent re- use of the medium by a lecturer.

The use of media materials in instruction does influence lecture preparation time, especially the first time a course is taught. Is time allowed for such preparation for new courses?

Typically, class presentations involving media materials integrate those materials within a personal verbal lecture. Slides and overhead transparencies are used to cue, summarise, illustrate, and provide focus during a lecture presentation.

Sixteen millimetre film is generally presented to provide a common class experience as a focus to stimulate class discussion.

Eight millimetre film, filmstrips, videotapes, audiotapes and computer programs were not used regularly by respondents in this study. Eight millimetre film and filmstrips are considered to be suitable only for school 
instruction. Audiotapes do not have enough attention-getting value to be frequently used in university instruction. Video tapes are used infrequently either in the same manner as $16 \mathrm{~mm}$ films or micro-teaching situations, and computers had not been easily accessible for integrating into instructional strategies by the respondents interviewed.

Many of the University of Oregon's classroom facilities are considered inadequate for media enhanced instruction. Though most of the respondents will try to 'make do' they feel a sense of frustration and sometimes avoid using media under poor conditions.

The attitudes of the personnel in the Instructional Media Centre can influence the extent to which a variety of media materials will be used in instruction A positive and helpful attitude can instil confidence and willingness to incorporate new media materials in course instruction.

\section{Implications of the study}

How media materials are used in instruction may differ between individual lecturers. Different approaches to teaching must be taken into account by administrators and Instructional Media Centre personnel. A lecturer will tend to use equipment and media resources more frequently if it is not a hassle to obtain either the hardware or the software.

The personal desire to use media materials to enhance a verbal presentation will lead a lecturer to produce or obtain suitable materials. Instructional Media Centre personnel should be available to help produce such personal materials and offer suggestions for product design, but not to impose a structure.

University and college administrators would do well to support the purchase of raw media materials and to supply production facilities with capable instructional technologists to work with lecturing staff as they produce personally relevant resources.

Lecturers with financial, human and moral support will integrate media materials within their verbal lecture presentations when they feel the subject matter will become more meaningful to students.

Further research should be carried out with lecturers in different institutions in order to generalise beyond the selected respondents from the University of Oregon. This study has offered an attempt to begin a consideration of the personal perceptions of lecturers related to how they use media materials in their university instruction. The next step is to interview students to seek their perceptions of how lecturers use media materials in instruction. 


\section{References}

Armsey, J.W. and Dahl, N.C. An Inquiry Into the Uses of Instructional Technology. Ford Foundation Report: New York, 1973.

Campeau, R.L. Selective review of the results of research on the use of audiovisual media to teach adults. AV Communications Review, 1974, 22 (1): 5-30.

Dodge, M. et al. How teachers perceive media. Educational Technology, 1974, 14: 21-24.

Garrison, J. The Use of Media in Lane Community College Classrooms, as Reported by Selected Instructors. M.A. Thesis, University of Oregon, 1982.

Jamison, D., Suppes, P., And Wells, S. The effectiveness of alternative instructional media: A survey. Review Of Educational Research, 1974, 44: 1-69.

Parkhurst, P.E. Generating meaningful hypotheses with aptitudetreatment interactions. AV Communications Review, 1975, 23 (2): 171-183.

Purdy, N.L. A Case Study of Acceptance and Rejection of Innovation by Faculty in a Community College. Ed.D. dissertation, University of California, 1973.

Purdy, N.L. Community college instructors and the use of new media: Why some do and others don't. Educational Technology, 1975, 15 (3): 9-12.

Russell, A.L. The Use of Media Materials in Instruction as Reported by Selected Faculty of the University of Oregon. Ph.D. dissertation. University of Oregon, 1981.

Schramm, W. The researcher and the producer in ETV. Public Telecommunications Review, 1977, 5 (4): 11-21.

Tobias, S. Lack of knowledge and fear of automation as factors in teachers' attitudes toward programmed instruction and other media. $A V$ Communications Review, 1966, 14: 99-109.

Tobias, S. Effects of attitudes to programmed instruction and other media on achievement from programmed materials. AV Communications Review, 1969, 17: 199-206.

Please cite as: Russell, A. (1985). How media materials are used in university instruction: Reports of selected university faculty members. Australian Journal of Educational Technology, 1(1), 47-58. http: / / www.ascilite.org.au/ajet/ajet1/russell.html 